\title{
Quantum Chemical Studies on Nicotinato Lead(II) Complex $\left[\mathrm{Pb}(\mathrm{II})\left(\mathrm{C}_{5} \mathrm{H}_{4} \mathrm{NCOO}_{2}\right]\right.$
}

\author{
Pu Su Zhao, Rong Qing Li, Jie Song, and Meng Ping Guo* \\ Jiangsu Kev Laboratory for Chemistrv of Low'-Dimensional Materials. Huaivin Teachers College, Huaian. Jiangsu 223300, \\ P.R. China. ${ }^{*}$ E-mail: zhaopusuiovahoo com.cn \\ ${ }^{\dagger}$ College of Chemistry and Bioengineering, Yichun University. Jiangxi. Yichun $336000, P$. R. China \\ Received September 4. 2007
}

\begin{abstract}
The title compound of nicotinato lead(II) complex $\left[\mathrm{Pb}\left(\mathrm{C}_{5} \mathrm{H}_{4} \mathrm{NCOO}\right)_{2}\right]$ has been optimized at B3LYP/ LANL2DZ and HF/LANL2DZ levels of theory. The calculated results show that the lead(II) ion adopts 2coordinate geometry. which is the same as its crystal structure and different from the 4-coordinate geometry of isonicotinato lead(II) complex. Atomic charge distributions indicate that during forming the title compound, each nicotinic acid ion transfers their negative charges to central lead(II) ion. The electronic spectra calculated by B3LYP/LANL2DZ level show that there exist two absorption bands, which have some red shifts compared with those of isonicotinato lead(II) complex and the electronic transitions are mainly derived from intraligand $\pi-\pi^{*}$ transition and ligand-to-metal charge transfer (LMCT) transition. CIS-HF method is not suitable for the system studied here. The thermody namic properties of the title compound at different tenperatures have been calculated and corresponding relations between the properties and temperature have also been obtained. The second order optical nonlinearity was calculated. and the molecular hyperpolarizability was $1.147754 \times 10^{-3 i}$, esu.
\end{abstract}

Key Words : Quantum chemical study. Lead(II) complex. Atomic charge distribution. Electronic absorption spectra. Second order optical nonlinearity'

\section{Introduction}

It is well known. lead has been used in electric storage batteries. paint pigments, gasoline additives, pipes, ammunition, solder. etc for many years due to its abundance and physical properties. which makes it be as one of the most important pollutants. ${ }^{1.2}$ On the other hand. since it is slowly eliminated. lead accumulates in liver. kidneys. bones, and other parts of the body. ${ }^{3}$ So, the design of drugs to counteract the effects of lead poisoning requires establishing the preferred ligands of $\mathrm{Pb}$ (II) and their stereochemistry. Consequently. synthesis of antidotes for lead(II) ion toxicosis has attracted more and more attention, and numerous reports concerning experimental coordination chemistry of lead(II) have been published. ${ }^{4.7}$ Nicotinic acid is a typical ligand for metallic ions and its biological importance has been described in several literatures. ${ }^{8.11}$ It can be used as antidote for lead(II) ion toxicosis, resulting in the formation of the title compound of nicotinato lead(II) complex $\left[\mathrm{Pb}\left(\mathrm{C}_{3} \mathrm{H}_{4} \mathrm{~N}\right.\right.$ $(\mathrm{COO})_{2}$ ]. However, for nicotinato lead(II). apart from its crystal structure reported by Cingi et al. in $1975^{11}$ there are no more experimental and theoretical studies on it available till now. As a matter of fact, with computational chemistry significantly advanced in the past decade, theoretical modeling of non-transition metal chemistry becomes nuch more mature than ever. Many important chemical and physical properties of chenical systems can be predicted from the first principles by various computational techniques. ${ }^{12} \mathrm{By}$ using quantum chemical calculations, we have made investigations on isonicotinato lead(II) comple ${ }^{13}$ and bis $(p$-aminobenzoato)-lead(II) conplex. ${ }^{\text {th }}$ Here. we wish to report the calculated results for the title compound of nicotinato lead(II) complex [ $\left.\mathrm{Pb}(\mathrm{II})\left(\mathrm{C}_{5} \mathrm{H}_{4} \mathrm{NCOO}\right)_{2}\right]$ and make a comparison with our early reports.

\section{Calculational Method}

The crystal structure of the title compound was used as initial molecular geometry, then it was optimized by using $\mathrm{MM}+$ molecular modeling and semi-empirical AMI methods $^{15}$ (HYPERCHEM 6.0. Hypercube. Ont., Canada). In the next step, $a b$ inito calculations with B3LYP/ LANL2DZ and HF/LANL2DZ levels of theory by the Berny method ${ }^{16}$ were perfomed with Gaussian 03 software package, ${ }^{17}$ respectively. The vibrational frequencies calculated prove that the structure is stable (no imaginary frequencies). The themodynamic properties of the title compound at different temperatures were obtained according to vibration analyses. Based on the optimized structure, electronic absorption spectra were predicted by using TDDFT $^{18.19}$ and CIS-HF ${ }^{20 j}$ methods. respectively. Natural Bond Orbital $(\mathrm{NBO})^{1,122}$ analyses were also performed on the optimized structure. By using couple-perturbed HartreeFork (CPHF) method. ${ }^{23.26}$ the molecular hyperpolarizability value was also calculated.

All calculations were performed on a Pentium IV computer and DELL PE2650 server using the default convergence criteria.

\section{Results and Discussion}

Optimized geometry. Figure 1 shows the molecular 


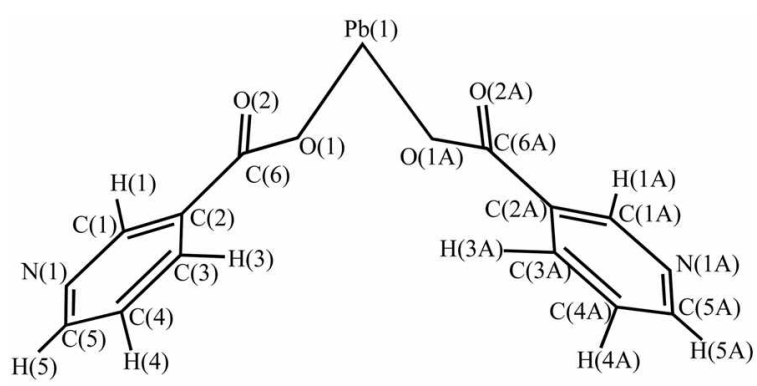

Figure 1. Molecular structure with atomic numbering scheme for the title complex.

Table 1. Selected structural parameters by $\mathrm{X}$-ray and theoretical calculations

\begin{tabular}{|c|c|c|c|}
\hline Bond length $(A)$ & Exp. & $\begin{array}{c}\text { B33LYP/ } \\
\text { LANL2DZ }\end{array}$ & $\begin{array}{c}\mathrm{HF} / \\
\mathrm{LANL} 2 \mathrm{DZ}\end{array}$ \\
\hline $\mathrm{Pb}(1)-\mathrm{O}(1)$ & $2.390(2)$ & 2.2679 & 2.2161 \\
\hline$C(6)-O(1)$ & $1.257(2)$ & 1.3247 & 1.3026 \\
\hline$C(6)-O(2)$ & $1.223(2)$ & 1.2977 & 1.2667 \\
\hline$C(6)-C(2)$ & $1.528(1)$ & 1.4783 & 1.4689 \\
\hline$C(2)-C(3)$ & $1.387(3)$ & 1.4113 & 1.3968 \\
\hline$C(3)-C(4)$ & $1.422(2)$ & 1.4040 & 1.3918 \\
\hline$C(4)-C(5)$ & $1.380(2)$ & 1.4096 & 1.3957 \\
\hline$N(1)-C(5)$ & $1.261(3)$ & 1.3597 & 1.3395 \\
\hline Bond angle ( $\left(^{\circ}\right)$ & Exp. & $\begin{array}{c}\text { B3LYP/ } \\
\text { LANL2DZ }\end{array}$ & $\begin{array}{c}\mathrm{HF} / \\
\mathrm{LANL} 2 \mathrm{DZ}\end{array}$ \\
\hline$O(1)-P b(1)-O(1 \mathrm{~A})$ & $82.64(2)$ & 90.5120 & 87.7902 \\
\hline$O(1)-C(6)-O(2)$ & $121.29(1)$ & 117.6075 & 116.5866 \\
\hline $\mathrm{O}(1)-\mathrm{C}(6)-\mathrm{C}(2)$ & $116.60(2)$ & 119.9047 & 120.1686 \\
\hline $\mathrm{C}(3)-\mathrm{C}(2)-\mathrm{C}(1)$ & $120.00(2)$ & 118.9297 & 119.0685 \\
\hline $\mathrm{C}(3)-\mathrm{C}(4)-\mathrm{C}(5)$ & $118.22(3)$ & 118.6394 & 118.4268 \\
\hline $\mathrm{C}(4)-\mathrm{C}(5)-\mathrm{N}(1)$ & $124.80(3)$ & 123.3499 & 123.0407 \\
\hline $\mathrm{C}(5)-\mathrm{N}(1)-\mathrm{C}(1)$ & $117.62(2)$ & 117.7516 & 118.6747 \\
\hline $\mathrm{N}(1)-\mathrm{C}(1)-\mathrm{C}(2)$ & $123.61(3)$ & 122.8001 & 122.2479 \\
\hline Torsion angle $\left({ }^{\circ}\right)$ & Exp. & $\begin{array}{c}\text { B3̂LYPf } \\
\text { LANL2DZ }\end{array}$ & $\begin{array}{c}\mathrm{HF} / \\
\text { LANL2DZ }\end{array}$ \\
\hline $\mathrm{Pb}(1)-\mathrm{O}(1)-\mathrm{C}(6)-\mathrm{O}(2)$ & $13.50(2)$ & 0.0471 & 1.549 \\
\hline$O(1)-C(6)-C(2)-C(3)$ & $13.75(1)$ & 0.0456 & 0.3551 \\
\hline $\mathrm{O}(2)-\mathrm{C}(6)-\mathrm{C}(2)-\mathrm{C}(1)$ & $13.30(2)$ & 0.3742 & 0.1026 \\
\hline$C(2)-C(3)-C(4)-C(5)$ & $1.70(1)$ & 0.043 & 0.0273 \\
\hline$C(2)-C(1)-N(1)-C(5)$ & $2.37(2)$ & 0.0839 & 0.0845 \\
\hline $\mathrm{C}(3)-\mathrm{C}(4)-\mathrm{C}(5)-\mathrm{N}(1)$ & $1.45(2)$ & 0.0686 & 0.0472 \\
\hline$C(4)-C(5)-N(1)-C(1)$ & $-0.04(2)$ & -0.0492 & -0.0195 \\
\hline
\end{tabular}

structure of the title compound with atomic numbering scheme. The selected optimized geometric parameters obtained at B3LYP/LANL2DZ and HF/LANL2DZ levels are listed in Table 1 . In view of the molecular symmetry. only half of the molecular geometric parameters are listed

Although the nicotinic acid molecule is also a typical chelated-form ligand just as the isonicotinic acid molecule. the $\mathrm{Pb}(\mathrm{II})$ ion in the title compound only adopts 2-coordinate geometry and is coordinated by two oxygen atoms from two nicotinic acid ions. which is the same as its crystal structure $^{11}$ and different from the 4-coordinate geometry of isonicotinato lead(II) complex $\left[\mathrm{Pb}\left(\mathrm{C}_{5} \mathrm{H}_{4} \mathrm{NCOO}\right)_{2}\right]^{13}$ The title complex has $C_{2}$ symmetry with two-fold axis passing through the $\mathrm{Pb}(\mathrm{II})$ ion and the centre of $\mathrm{O}(\mathrm{I})$ and $\mathrm{O}(\mathrm{IA})$ atoms, which is the same as that in the isonicotinato lead(II) complex. ${ }^{13}$ In view of the bond lengths, all of values obtained by HF/LANL2DZ are shorter than those by B3LYP/LANL2DZ and most of the theoretical values are longer than those of experimental values. The biggest difference between the experimental and theoretical values mainly occurs at bond of $\mathrm{Pb}(\mathrm{I})-\mathrm{O}(\mathrm{l})$, with the predicted value shorter than the experimental value being $0.1221 \AA$ for B3LYP method and $0.1739 \AA$ for HF method. As for the bond angles, the theoretical values obtained by two methods are comparative and the biggest different between the experimental and theoretical values mainly takes place at $\mathrm{O}(\mathrm{l})-\mathrm{Pb}(\mathrm{l})-\mathrm{O}(\mathrm{IA})$ bond angle, with the predicted value bigger than the experimental value being $7.872^{\circ}$ for B3LYP method and $5.1502^{\circ}$ for HF method. Seen from the torsion angles listed in Table 1, for each nicotinic acid ion, all of the atoms are almost coplanar with the $\mathrm{Pb}(\mathrm{II})$ ion. which is slightly different from that in the crystal structure. ${ }^{11}$ It is evident that in the solid state. the exist of crystal field makes the molecule of nicotinato lead(II) complex $\left[\mathrm{Pb}\left(\mathrm{C}_{5} \mathrm{H}_{4} \mathrm{NCOO}\right)_{2}\right]$ have some torsions, while in the calculations, the molecule is in the gas-phase at $0 \mathrm{~K}$ and interactions among molecules are ignored. Despite of the differences mentioned above. the optimized geometries can reproduce the crystal structure on the whole. which are the bases for our discussion below.

Atomic charge distributions. At B3LYP/LANL2DZ and HF/LANL2DZ levels of theory. the NPA atomic charge distributions on the atoms of the title complex and nicotinic acid ion are calculated based on the optimized structures and listed in Table 2 (in view of the molecular symmetry. only one nicotinic acid ion is given).

Comparing the atomic charges in the title compound with those in each free nicotinic acid ion. one can find that the

Table 2. NPA atomic charge distributions for the title complex and nicotinic acid ion

\begin{tabular}{lcccr}
\hline Atom & \multicolumn{2}{c}{$\mathrm{B} 3 \mathrm{LYP} / \mathrm{LANL} 2 \mathrm{DZ}$} & \multicolumn{2}{c}{$\mathrm{HF} / \mathrm{LANL} 2 \mathrm{DL}$} \\
\hline & {$[\mathrm{Pb}(\mathrm{II})$} & $\left.\mathrm{C}_{5} \mathrm{H}_{4} \mathrm{NCO}\right)^{-}$ & {$[\mathrm{Pb}(\mathrm{II})$} & $\mathrm{C}_{5} \mathrm{H}_{4} \mathrm{NCOO}^{-}$ \\
& $\left.\left(\mathrm{C}_{5} \mathrm{H}_{+} \mathrm{NCOO}\right)_{2}\right]$ & & $\left.\left(\mathrm{C}_{5} \mathrm{H}_{+} \mathrm{NCOO}\right)_{2}\right]$ \\
$\mathrm{Pb}(1)$ & 1.47534 & & 1.64547 \\
$\mathrm{~N}(1)$ & -0.49249 & -0.53138 & -0.54803 & -0.57741 \\
$\mathrm{C}(1)$ & 0.10215 & 0.06085 & 0.16277 & 0.11303 \\
$\mathrm{C}(2)$ & -0.19335 & -0.15257 & -0.24901 & -0.19393 \\
$\mathrm{C}(3)$ & -0.14362 & -0.18529 & -0.09567 & -0.14623 \\
$\mathrm{C}(4)$ & -0.25165 & -0.27920 & -0.27968 & -0.29889 \\
$\mathrm{C}(5)$ & 0.07035 & 0.01601 & 0.12951 & 0.06703 \\
$\mathrm{C}(6)$ & 0.82276 & 0.77601 & 0.99775 & 0.96132 \\
$\mathrm{O}(1)$ & -0.82443 & -0.78624 & -0.96752 & -0.89777 \\
$\mathrm{O}(2)$ & -0.75860 & -0.77877 & -0.87223 & -0.88940 \\
$\mathrm{H}(1)$ & 0.23415 & 0.22516 & 0.22783 & 0.22799 \\
$\mathrm{H}(3)$ & 0.24909 & 0.24112 & 0.24248 & 0.24443 \\
$\mathrm{H}(4)$ & 0.23099 & 0.20476 & 0.22188 & 0.20279 \\
$\mathrm{H}(5)$ & 0.21698 & 0.18953 & 0.20720 & 0.18704 \\
\hline
\end{tabular}


Table 3. Calculated electronic absorption spectra values

\begin{tabular}{|c|c|c|c|c|c|c|c|}
\hline \multicolumn{4}{|c|}{ TD-DFT } & \multicolumn{4}{|c|}{ CIS-HF } \\
\hline \multicolumn{2}{|c|}{ the title compound } & \multicolumn{2}{|c|}{ tree ligand of nicotivic acid ion } & \multicolumn{2}{|c|}{ the title compound } & \multicolumn{2}{|c|}{ tree ligand of nicotinic acid ion } \\
\hline $\begin{array}{l}\text { wavelength } \\
\text { (nm) }\end{array}$ & $\begin{array}{l}\text { oscillator } \\
\text { strength }\end{array}$ & $\begin{array}{l}\text { wavelength } \\
\text { (11m) }\end{array}$ & $\begin{array}{l}\text { oscillator } \\
\text { strength }\end{array}$ & $\begin{array}{l}\text { wavelength } \\
\text { (nm) }\end{array}$ & $\begin{array}{l}\text { oscillator } \\
\text { strength }\end{array}$ & $\begin{array}{l}\text { wavelength } \\
\text { (nim) }\end{array}$ & $\begin{array}{l}\text { oscillator } \\
\text { strength }\end{array}$ \\
\hline 253.62 & 0.1415 & 234.37 & 0.0309 & 200.47 & 0.4308 & 200.59 & 0.0778 \\
\hline 24804 & 0.1118 & & & & & & \\
\hline 231.25 & 0.3095 & 211.40 & 0.1653 & & & & \\
\hline
\end{tabular}

atomic charge redistributions occur on all of the atoms. In order to form the title complex of $\left[\mathrm{Pb}\left(\mathrm{C}_{5} \mathrm{H}_{4} \mathrm{NCOO}\right)=\right]$, each free ligand of nicotinic acid ion transfers their electrons to the central $\mathrm{Pb}$ (II) ion and the transferred electronic numbers are $-0.26233 e$ in B3LYP/LANL2DZ calculations and $-0.17727 e$ in HF/LANL2DZ calculations. Namely, during forming the title complex. the central $\mathrm{Pb}$ (II) ion accepts $-0.52466 e$ (B3LYP) and $-0.3545+e$ (HF) negative charges from nicotinic acid ion. respectively. Maybe it is one of the reasons that the change of atomic charges on the lead ion results in the $\mathrm{Pb}$ (II) ion losing its toxicity on intelligence in human populations.

Electronic absorption spectra. Electronic absorption spectra values calculated for the title compound and the free ligand of nicotinic acid ion by using TD-DFT method and CIS-HF method are given in Table 3. By using CIS-HF method, the electronic transition bands for the title complex $(200.47 \mathrm{~nm})$ and the free ligand of nicotinic acid ion (200.59 Int) are almost the same. To some extent. for coordination complex. this result is not corresponding to the ordinary rule of electronic absorption spectra and we can deduce that CISHF method is not suitable for predicting the electronic spectra for the system studied here. For the title complex. the B3LYP/LANL2DZ calculated results show that there are two absorption bands. one broad shoulder band is from 253.62 to $248.04 \mathrm{~nm}$ and another peak is at $231.25 \mathrm{~mm}$, both of which are shifted to lower energy corresponding to the free ligand of nicotinic acid ion. Natural population analyses indicate that the frontier molecular orbitals are mainly composed of $p$ atomic orbitals. so above electronic transitions are mainly derived from the contribution of intraligand (IL) $\pi \cdot \pi$ transition and ligand-to-metal charge transfer (LMCT) transition, which are similar with those in the isonicotinato lead(II) complex. ${ }^{13}$ Compared with the electronic absorption spectra of the free ligand of isonicotinic acid ion (232.05 and $209.11 \mathrm{~mm})^{13}$ two electronic spectra peaks of free ligand of nicotinic acid ion have some red shifts, respectively. The similar situation can be found between the isonicotinato lead(II) complex and nicotinato lead(II) complex, where the two electronic spectra bands of the later (Table 3 ) have some red shifts compared with those of the fomer [227.32-224.40 $1 \mathrm{um}$ (broad) and $218 \mathrm{~nm}$ (narrow) ${ }^{13}$ Aforementioned phenomena indicate that conjugative effects between the pyridine ring and the carboxylic group in the nicotinic acid ion are stronger than those in the isonicotinic acid ion. Figure 2 shows the surfaces of HOMO. HOMO-1. LUMO and LUMO+1 of the title complex. Seen from Figure 2. HOMO

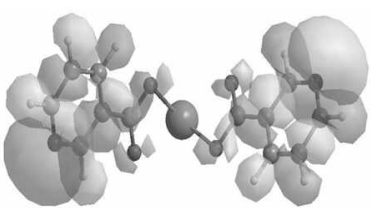

HOMO-1

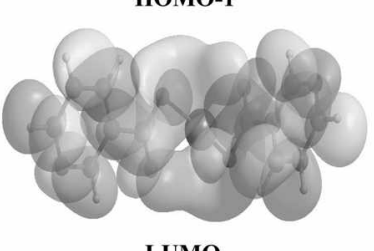

LUMO

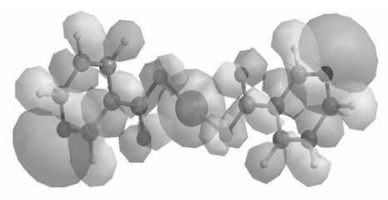

HOMO

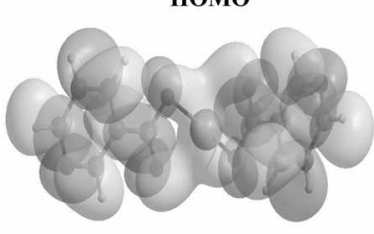

LUMO+1
Figure 2. Some frontier molecular orbital stereographs for the title complex.

and HOMO-I of the title complex are principally delocalized among the atoms of nicotinic acid ion, while LUMO and LUMO+ $\mathrm{l}$ are delocalized among the atoms of nicotinic acid ion as well as the $\mathrm{Pb}$ (II) ion. Namely. as a non-transition metal complex. the title compound has no electronic transition band located at visible light range. indicating that the fully occupied $d$ atomic orbitals of the lead(II) ion do not take part in the electronic transitions. However, during the electronic transition. the outer $p$ orbitals have to assist the charges transfer, which will finally change the electronic cloud shape of $\mathrm{Pb}(\mathrm{II})$ ion and maybe finally decrease its ability to influence the intelligence of people.

Thermodynamic properties. Based on vibrational analysis at B3LYP/LANL2DZ level and statistical thermodynamics. for the title compound. standard thermodynamic functions-heat capacity $\left(C_{p . m}^{i}\right)$. entropy $\left(S_{\mathrm{m}}^{\mathrm{ij}}\right)$ and enthalpy $\left(H_{\mathrm{m}}^{\mathrm{i}}\right)$ were obtained using our own program and listed in Table 4. The scale factor for frequencies is 0.96 , which is a

Table 4. Thermodynamic properties of the title compound at different temperatures at B3LYP/L ANL2DZ level

\begin{tabular}{cccc}
\hline$T / \mathrm{K}$ & $\mathrm{C}^{0}{ }_{p . r n}(\mathrm{~T} / \mathrm{mol} \mathrm{K})$ & $S^{0}{ }_{m}(\mathrm{~T} / \mathrm{mol} \mathrm{K})$ & $H^{0}{ }_{m r}(\mathrm{k} \mathrm{T} / \mathrm{mol})$ \\
\hline 2000 & 200.13 & 515.05 & 25.48 \\
298.1 & 269.86 & 607.91 & 48.54 \\
3000 & 271.17 & 609.58 & 49.04 \\
4000 & 337.34 & 696.89 & 79.54 \\
5000 & 391.91 & 778.25 & 116.11 \\
6000 & 434.87 & 853.66 & 157.54 \\
700.0 & 468.59 & 923.33 & 202.78 \\
8000 & 495.44 & 987.72 & 251.03 \\
\hline
\end{tabular}


typical scale factor for the B3LYP/LANL2DZ level of calculations.

As observed from Table 4 , standard heat capacities. entropies and enthalpies increase at any temperature from 200.0 to $800.0 \mathrm{~K}$, due to that the intensities of molecular vibration increase while the temperature increases. Compared with the isonicotinato lead(II) complex, ${ }^{13}$ although they have the same molecular weight, the title conpound has the bigger values of $S_{m}^{i j}$ and $H_{m}^{i}$ than isonicotinato lead(II) complex at any temperature. As for the $C_{p, m}^{\prime}$, before 400.0 $K$. the $C_{p, m}^{i}$ values of the title compound are bigger than those of isonicotinato lead(II) complex. while after $400.0 \mathrm{~K}$. the $C_{p, m}^{j}$ values of the title compound are smaller than those of isonicotinato lead(II) complex. For the title compound. the correlation equations between these thermodynamic properties and temperature $T$ are obtained by using the leastsquares method and listed as follows:

$$
\begin{aligned}
& C_{p . m}^{j}=42.3060+0.8958 \mathrm{~T}-4.088 \mathrm{I} \times 10^{-4} \mathrm{~T}^{2} . \\
& S_{m}^{j}=295.2000+1.1495 \mathrm{~T}-3.5832 \times 10^{-4} \mathrm{~T}^{2}, \\
& H_{m}^{\prime j}=-6.3260+0.1081 \mathrm{~T}-2.6982 \times 10^{-4} \mathrm{~T}^{2} .
\end{aligned}
$$

These equations will be helpful for the further studies of the title compound. For instance. when we go on to investigate the interactions between the title complex and DNA, above thermodynamic properties of $S_{m}^{i}$ and $H_{m}^{i j}$ will be used to calculate the change of Gibbs free energy of the reaction and assist us to judge the spontaneity of the reaction. This work is in progress by our group.

Nonlinear optical property calculations. Using coupleperturbed Hartree-Fock (CPHF)method. ${ }^{23.36}$ the molecular first hyperpolarizability value. $\beta_{\mu}$, the vector component along the dipole moment direction. of the title compound was calculated to be $1.147754 \times 10^{-3(1)} \mathrm{esu}$, which is greater than that of urea $\left(0.72137 \times 10^{-51)}\right.$ esu. calculated using the same method) and smaller than that of isonicotinato lead(II) complex $\left(3.62365 \times 10^{-3(1)} \mathrm{esu}\right) \cdot{ }^{1 \hat{3}}$ This result suggests that the studied coniplex is a noncentrosymmetric compound and atonic charge transfers exist universally among all the atoms of the compound. which are consistent with the discussion above. During the process of electronic transition. the $\mathrm{Pb}(\mathrm{II})$ ion acts as a bridge to participate in the electron transfer, resulting in the loss of the $\mathrm{Pb}(\mathrm{II})$ ion toxicity on intelligence in human populations.

\section{Conclusions}

$A b$ initio calculations have been performed on the title compound of $\left[\mathrm{Pb}(\mathrm{II})\left(\mathrm{C}_{5} \mathrm{H}_{4} \mathrm{NCOO}\right)_{2}\right]$ by using B3LYP and HF methods with LANL2DZ basis set. The calculated results indicate that both the optimized geometries adopt 2 coordinate conformation with $C_{2}$ symmetry, which can reproduce the crystal structure on the whole. NPA atomic charge distributions show that during forming the title complex. the two free ligands of nicotinic acid ion have transferred their charges to the central $\mathrm{Pb}(\mathrm{II})$ cation and all of the atoms of the title compound take part in the charge redistributions. Electronic absorption spectra calculations suggest that CIS-HF method is not suitable for the system studied here. while TD-DFT method can give two reasonable absorption bands. which can mainly assigned to intraligand (IL) $\pi-\pi^{*}$ transition and ligand-to-metal charge transfer (LMCT) transition. Based on vibrational analysis, the thermodynamic properties of $C_{p, m}^{j}$. $S_{m}^{i}$ and $H^{i j}{ }_{n}$ at different temperatures have been calculated and the correlation equations between these thermodynamic properties and temperature $T$ are also obtained. By using CPHF method. the molecular first hyperpolarizability value was predicted to be $1.147754 \times 10^{-313} \mathrm{esu}$, which is greater than that of urea.

Acknowledgments. This work was supported by Natural Science Foundation of the Department of Education of Jiangsu Province P. R. China (06KJD1500030), Huaian Science \& Teclunology Bureau. Jiangsu Province. P. R. China (HAG05039) and Fund of Huanyin Teachers College (06HSIS024, 07HSBS004).

\section{References}

1. Lanphear. B. P. Science 1998. 281. 1617

2. Lanphear. B. P.: Roghmann. K. J. Ewiwon. Res. 1997. 74, 67.

3. Sigel, H; Da Costa, C. P.: Martin, R. B. Coord. Chem. Rev 2001. 435. 219 .

4. Wang. T.: Liu. Z. R.: Zhang. X. D.: Tia. W. G: Fan. D. M. Chinese J. Stuct Chem. 2003. 22. 454

5. Fleischer. H.: Schollmeyer. D. Inorg. Chem. 2004. +3. 5529

6. Li. H. H.: Chen, Z. R: Li. J. Q.: Huang. C. C: Zhao, B.: Ni, Z. X Chinese J. Struct. Chem. 2005, 24. 39

7. Hancock. R. D.: Reibenspies. J. H.: Maumela, H. horg. Chem. 2004. +3. 2981

8. Wang. W.: Basinger. A.: Shane. B.: Myong. S. A.: Christiansen. M.: Hellerstein. M. Am. J. Phwsiol. 2001. 280. 540 .

9. Berg, I; Potter. B. J. Cell Biol. 2000. 150, 581.

10. Ahren, B. Acta Plysiol. Scand. 2001, 171, 161.

11. Cingi, M. B.: Manfredotti. A. G.; Guastini, C.: Musatti. A. Gazz. Chint Ital. 1975. 105.117.

12. Lipkowitz. K. B.: Boyd. D. B. Reviews in Conputational Chentistry: VCH: New York. 1990-1999: Vols. 1-13.

13. Zhao. P. S.; Jian. F. F; Li. C. L.: Zheng. J. Chinese d. Struct. Chem. 2006, 25, 657

14. Zhao. P. S.: Xu. J. M.; Li, R. Q.: Cai. Z. J. Polish J. Chem. 2007. 81.85

15. Dewar. M. J. S.: Zoebisch. E. G. Healy. E. F. J. Am. Chen. Soc. 1985. 107.3902.

16. Peng. C.: Avala. P. Y: Schlegel. H. B.; Frisch. M. J. J. Conput. Chem $1996,17,49$

17. Frisch. M. J.: Trucks. G. W: Scllegel. H. B.: Scuseria, G. E: Robb. M. A.: Cheeseman. J. R.: Montgomery. J. A.: Vreven. Ir.. T:: Kudin. K. N.: Burant. T. C.: Millam. J. M.: Iyengar. S. S.: Tomasi. J.: Barone. V: Mennucei. B.: Cossi. M.: Scalmani. G.: Rega. N.: Petersson. G. A.; Nakatsuji, H.; Hada. M.: Ehara. M: Toyota, K; Fukuda, R; Hasegawa, J.: Ishida. M.: Nakajima. T; Honda, Y; Kitao. O.: Nakai. H.; Klene, M: Li, X; Knox. J. E: Hratchian. H. P.: Cross. T. B.: Adamo. C.: Taramillo. T.: Gomperts. R.: Stratmann. R. E:: Yazyev. O: Austin. A. J: Cammi. R: Pomelli. C.: Ochtershi. J. W: Ayala. P. Y.: Morokuma. K.: Voth. G. A.; Salvador, P.; Dannenterg, J. J:; Zakrzewski. V. G: Dapprich, S.; Daniels, A. D.; Strain, M. C.: Farkas. O : Malick, D. K; Rabuck. A. D.: Raghavachari, K; Foresman. J. B; Ortiz, J. V: Cui. Q.: Baboul. A. G.: Clifford. S.: Cioslowski. I.: Stefanow. B. 
B.: Liu. G.: Liashenko. A.: Piskorz. P.: Komaromi. I.: Martin. R. L.: Fox. D. J.: Keith. T.: Al-Laham. M. A.: Peng. C. Y: Nanayakkara. A.: Challacombe. M.: Gill. P. M. W. Johnson. B: Chen, W. Wong. M. W. Gonzalez. C.: Pople. J. A. Gaussian, Inc.: Wallingford CT, 2004.

18. Bauernschnnitt. R: Ahlrichs. R. Chem. Ptys. Lett. 1996, 256. 454.

19. Casida. M. E.: Jamorski. C.: Casida. K. C.: Salahub. D. R. J. Chem. Plvs. 1998. 108. 4439.

20. Foresman, I. B.: Head-Gordon, M: Pople. J. A: Frisch. M. I. J.
Phos Chem. 1992.96.135.

21. Reed. A. E.: Curtiss. L. A.: Weinhold. F. Chent. Rev: 1988. 88. 899.

22. Reed. A. E: Weinstoxk. R. B:; Weinhold, F. J. Chom. Phys. 1985. 83.735.

23. Gerratt, J Mills, I. M. J. Chem Plys. 1968, 19. 1719.

24. Pulay. P. J. Chent Phss. 1983. 78. 5043.

25. Osamura. Y.: Yamaguchi. Y.: Schaefer. II. H. F. J. Chem. Phys. 1982. 77. 383 .

26. Dykstra, C. E.: Jasien. P. G. Chem. Plys. Lett. 1984. 109, 388. 